\title{
Characteristics and mechanisms of sorption of organic contaminants onto sodium dodecyl sulfate modified Ca-Al layered double hydroxides
}

\author{
RUAN XiuXiu, SUN Peng, OUYANG XingXing \& QIAN GuangRen* \\ School of Environmental and Chemical Engineering, Shanghai University, Shanghai 200444, China
}

Received December 12, 2010; accepted May 9, 2011

\begin{abstract}
A series of calcium aluminum layered double hydroxides (LDHs) modified with sodium dodecyl sulfate (SDS) (Ca/Al-SDSLDHs) were synthesized by co-precipitation, and characterized by X-ray diffraction, Fourier transform infrared spectroscopy, and elemental analysis. The Ca/Al-SDS-LDHs enhanced sorption of nitrobenzene and naphthalene from water compared with inorganic LDH (Ca/Al-Cl-LDH). The sorption isotherms for sorption of organic contaminants onto the Ca/Al-SDS-LDHs were linear for the concentration range tested, which implies that the sorption mechanism is mainly by partition. The sorption of naphthalene onto Ca/Al-SDS-LDH was apparently stronger than that of nitrobenzene, but this order reversed after eliminating the hydrophobic effect of these two contaminants. Because naphthalene is non-polar and nitrobenzene is polar, the results indicate that the $\mathrm{Ca} / \mathrm{Al}-$ SDS-LDHs were selective for polar organic contaminants.
\end{abstract}

layered double hydroxide, SDS, sorption, nitrobenzene, naphthalene, co-precipitation

Citation: $\quad$ Ruan X X, Sun P, Ouyang X X, et al. Characteristics and mechanisms of sorption of organic contaminants onto sodium dodecyl sulfate modified Ca-Al layered double hydroxides. Chinese Sci Bull, 2011, 56: 3431-3436, doi: 10.1007/s11434-011-4762-y

Layered double hydroxides (LDHs) or hydrotalcite-like compounds are a class of natural and synthetic lamellar compounds with the general formula $\left[\mathrm{M}^{2+}{ }_{1-x} \mathrm{M}^{3+}{ }_{x}(\mathrm{OH})_{2}^{-}\right]^{x+}$ $\left[\mathrm{A}^{n-}{ }_{x / n}\right] m \mathrm{H}_{2} \mathrm{O}$, where $\mathrm{M}^{2+}=\mathrm{Mg}^{2+}, \mathrm{Ca}^{2+}, \mathrm{Ni}^{2+}, \mathrm{Cu}^{2+}, \mathrm{Zn}^{2+}$, $\mathrm{Co}^{2+}$ and $\mathrm{M}^{3+}=\mathrm{Al}^{3+}, \mathrm{Fe}^{3+}, \mathrm{Cr}^{3+}$; and $\mathrm{A}^{n-}$ is an anion such as $\mathrm{CO}_{3}{ }^{2-}, \mathrm{SO}_{4}{ }^{2-}, \mathrm{NO}_{3}^{-}$, or an organic anion [1]. Some of the $\mathrm{M}^{2+}$ ions in LDHs are substituted by $\mathrm{M}^{3+}$ ions, which produces positively charged layers with the composition $\left[\mathrm{M}^{2+}{ }_{1-x} \mathrm{M}^{3+}{ }_{x}(\mathrm{OH})_{2}^{-}\right]^{x+}$. To compensate for the positive charges on these layers, $\mathrm{A}^{n-}$ are intercalated in the structure. LDHs have been investigated because of their potential applications as ion-exchangers [2-6] and catalysts [7].

LDHs can be used to remove contaminants from the environment. However, hydrophilic hydroxyl groups on the LDH surface reduce the sorption performance for hydrophobic non-ionic organic contaminants $[8,9]$. To enhance the sorption of non-ionic organic contaminants, anionic

*Corresponding author (email: grqian@ shu.edu.cn) surfactants such as the anions of dodecyl sulfate $\left(\mathrm{DS}^{-}\right)$and dodecylbenzenesulfonic acid $\left(\mathrm{DBS}^{-}\right)$have been inserted into $\mathrm{Mg}-\mathrm{Al} / \mathrm{Li}-\mathrm{Al} / \mathrm{Zn}-\mathrm{Al} \mathrm{LDHs}$ [10-18]. Anionic surfactant intercalated LDHs can be prepared by the ion exchange method, using $\mathrm{LDH}-\mathrm{Cl}$ or $\mathrm{LDH}-\mathrm{NO}_{3}$ as the precursors. The carboxylic acids are believed to assist the intercalation process by facilitating the elimination of carbonate ions [19]. The intercalation capacity of $\mathrm{DBS}^{-}$into $\mathrm{Mg} / \mathrm{Al}-\mathrm{NO}_{3}-\mathrm{LDH}$ was greater than that of $\mathrm{DS}^{-}$, which indicates that increasing the $\mathrm{SO}_{3}^{-}$content on the surfactant will increase its intercalation capacity [20].

Modification of anionic surfactants has been used to improve the removal efficiencies of organic contaminants by LDHs. Excellent sorption of 2-naphthol onto SDS-modified $\mathrm{Mg}-\mathrm{Al}-\mathrm{Cl}-\mathrm{LDH}$ was used to propose a solubilization theory, in which the solubility of the organic compounds increased after sorption onto LDHs and this increased transfer of the organic compounds from water to the LDHs [21]. For example, the sorption of carbetamide and metamitron onto 
SDS modified Mg-Al LDH was enhanced when the quantity of intercalated $\mathrm{DS}^{-}$increased [22]. The sorption of the dye Green Bezanyl-F2B on Mg/Al-SDS-LDH by the calcination-rehydration method has also been studied, and the sorption isotherms were fitted to the Langmuir and Freundlich equations [23]. The mechanism for the adsorption of chlorpyrifos (CPF) onto DBS-LDHs was believed to be related to the hydrophobicity of the DBS-LDHs, but $\pi-\pi$ interactions between the pyridine ring of CPF and the benzene ring of DBS may also be important [24]. Intercalation of surfactants into Mg-Al LDH was found to decrease the specific surface area of $\mathrm{Mg}-\mathrm{Al} \mathrm{LDH}$, whereas surfactants dramatically enhanced the LDH affinity for 1,2,4-trichlorobenzene and 1,1,1-trichloroethane in aqueous solutions. The sorption characteristics of 1,2,4-trichlorobenzene and 1,1,1-trichloroethane onto organo-LDH indicated that sorption occurred by the partition mechanism [25]. 2,4-Dichlorophenol was considerably solubilized in the anionic surfactant layers intercalated in hydrotalcite. The bis[2ethylhexyl] sulfosuccinate-hydrotalcite complex appeared to be a more effective adsorbent for 2,4-dichlorophenol than the dodecyl sulfate-hydrotalcite complex [26].

Many studies have investigated the sorption of organic contaminants by anionic surfactant-modified LDHs with different $\mathrm{M}^{2+} / \mathrm{M}^{3+}$ ratios. The results have shown that the sorption of organic contaminants onto organic LDHs is influenced by the $\mathrm{M}^{2+} / \mathrm{M}^{3+}$ ratio. For example, the sorption of trichloroethylene and tetrachloroethylene by $\mathrm{Mg} / \mathrm{Al}-\mathrm{SDS}$ LDHs was stronger on $\mathrm{Mg}_{3} \mathrm{Al}-\mathrm{SDS}-\mathrm{LDH}$ than on $\mathrm{Mg}_{2} \mathrm{Al}-$ SDS-LDH [27]. However, there are many different kinds of organic contaminants in the environment, and the effect of the different properties of these organic contaminants on their sorption by LDHs has not been investigated. Further research is required in this area.

To optimize the use of LDHs for contaminant removal from the environment, it is necessary to understand how the characteristics and mechanisms of sorption are affected by different contaminants. In this work, the sorption of polar (nitrobenzene) and non-polar (naphthalene) organic contaminants by $\mathrm{Ca} / \mathrm{Al}-\mathrm{Cl}-\mathrm{LDH}$ and $\mathrm{Ca} / \mathrm{Al}-\mathrm{SDS}-\mathrm{LDH}$ were studied.

\section{Materials and methods}

\subsection{Materials}

All the chemicals used in this study, including $\mathrm{CaCl}_{2}$, $\mathrm{AlCl}_{3} \cdot 6 \mathrm{H}_{2} \mathrm{O}, \mathrm{NaOH}$, sodium dodecyl sulfate, nitrobenzene, and naphthalene, were analytical grade. All the aqueous solutions were prepared in double-distilled water.

\subsection{Methods}

(1) Samples preparation. A series of Ca/Al-SDS-LDHs were prepared by co-precipitation. Aqueous solutions of
$\mathrm{CaCl}_{2}$ and $\mathrm{AlCl}_{3}$ with various $\mathrm{Ca} / \mathrm{Al}$ amount-of-substance ratios $(\mathrm{Ca} / \mathrm{Al}=2: 1,1: 1,1: 2$, and $1: 3)$ were prepared. These solutions were added dropwise with $\mathrm{NaOH}$ solution (100 $\mathrm{mL}, 1.5 \mathrm{~mol} / \mathrm{L}$ ) to a $500 \mathrm{~mL}$ flask containing $0.2 \mathrm{~mol} / \mathrm{L}$ SDS with vigorous stirring at $25^{\circ} \mathrm{C}$. The mixture was shaken at

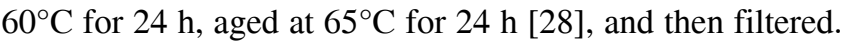
The residue was washed with double-distilled water three times, then dried at $105^{\circ} \mathrm{C}$ for $24 \mathrm{~h}$ and ground to 100 mesh. The samples prepared from $\mathrm{Ca} / \mathrm{Al}=2: 1,1: 1,1: 2$, and $1: 3$ were labeled S1, S2, S3, and S4, respectively.

A Ca/Al-Cl-LDH sample was prepared by the same method using $100 \mathrm{~mL}$ of $\mathrm{NaOH}$ solution $(1.5 \mathrm{~mol} / \mathrm{L})$ and an aqueous solution of $\mathrm{CaCl}_{2}$ and $\mathrm{AlCl}_{3}(\mathrm{Ca} / \mathrm{Al}=2: 1)$.

All the samples were stored in a vacuum desiccator.

(2) Sample characterization. The samples were analyzed by powder X-ray diffraction (XRD) using a Rigaku D/MAX2200 X-ray diffractometer (Rigaku, Tokyo, Japan) under the following conditions: $40 \mathrm{kV}, 40 \mathrm{~mA}$, and $\mathrm{Cu} \mathrm{K \alpha}$ $(\lambda=0.15406 \mathrm{~nm})$ radiation. The samples, as unoriented powders, were scanned in $0.02^{\circ}(2 \theta)$ steps from $1^{\circ}$ to $15^{\circ}$ at $1 \%$ min.

Elemental analysis was performed on a Eurovector EA3000 automatic elemental analyzer (Eurovector, Milan, Italy).

Fourier transform infrared (FT-IR) spectroscopy was carried out using a Nicolet 380 FT-IR spectrometer (Thermo Fischer Scientific, Waltham, MA). Samples were analyzed as $\mathrm{KBr}$ discs with a $1 \%$ compound loading. The spectra were recorded between 4000 and $400 \mathrm{~cm}^{-1}$.

(3) Sorption experiments. Sorption experiments were conducted in $25 \mathrm{~mL}$ centrifuge tubes. After adding $0.1 \mathrm{~g}$ of sorbent and $20 \mathrm{~mL}$ of an aqueous solution containing various quantities of organic contaminants (nitrobenzene and naphthalene), the tubes were shaken at $25^{\circ} \mathrm{C}$ for $4 \mathrm{~h}$ to attain equilibrium. After centrifugation, the concentrations of the organic contaminants in the supernatant were determined by UV-Vis spectroscopy (Unic UV-4802H) using the peaks at $270 \mathrm{~nm}$ (nitrobenzene) and $219 \mathrm{~nm}$ (naphthalene). All samples were analyzed in triplicate.

\section{Results and discussion}

\subsection{Characteristics of the Ca/Al-SDS-LDHs}

The Ca/Al-SDS-LDHs were characterized by XRD, FT-IR spectroscopy, and elemental analysis (EA). The XRD patterns of the LDH samples are shown in Figure 1. The three peaks observed for the samples indicated that all these samples had layered structures. The $d_{003}$ value of $\mathrm{Ca} / \mathrm{Al}-\mathrm{Cl}-\mathrm{LDH}$ was $0.76 \mathrm{~nm}$. However, the $d_{003}$ values of S1, S2, S3 and S4 were $3.31,3.12,3.98$ and $4.18 \mathrm{~nm}$, respectively. Compared with $\mathrm{Ca} / \mathrm{Al}-\mathrm{Cl}-\mathrm{LDH}$, the interlayer spacings of the $\mathrm{Ca} / \mathrm{Al}$ SDS-LDHs were much larger because of the SDS modification. 


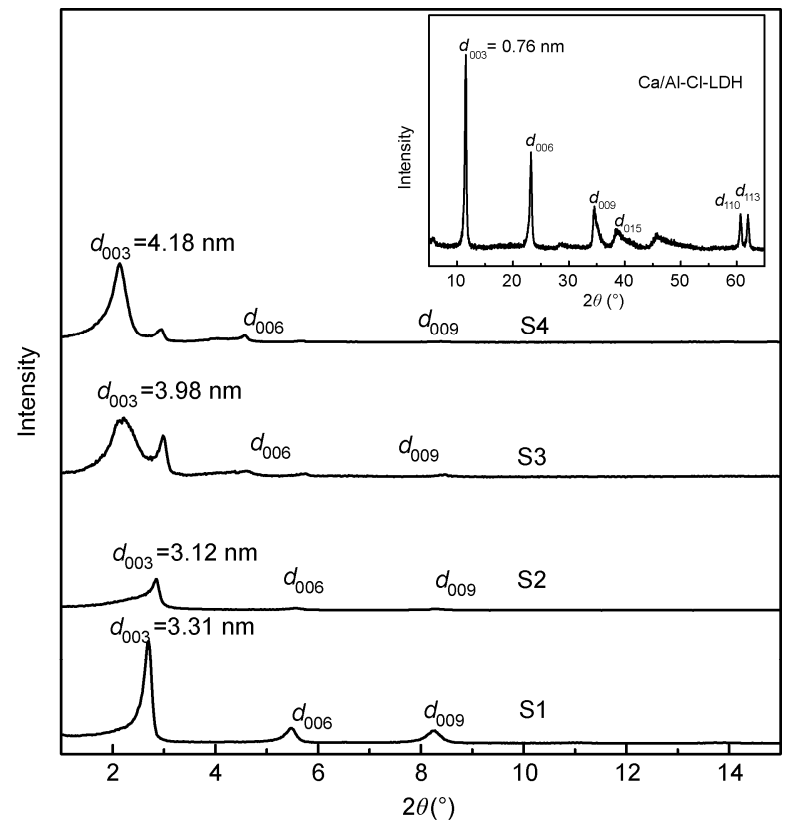

Figure 1 XRD patterns of the Ca/Al-LDHs.

The XRD pattern of S1 appeared to be much more crystalline than the other samples. This ordered layer structure of S1 might aid sorption of aqueous organic contaminants. As shown in Figure 1, the crystal structure of S3 was the least ordered and the $d_{003}$ value of S2 was the lowest. Sample S4 had the largest $d_{003}$, which indicates that this sample has the largest interlayer spacing, which would provide a space for intercalation of organic molecules in the LDHs during the sorption process.

The presence of anionic surfactants in the organic LDH structure can be further supported by the FT-IR spectra (Table 1). Pure SDS showed four characteristic bands. The bands at around 2959 and $2850 \mathrm{~cm}^{-1}$ were $v_{\mathrm{C}-\mathrm{H}}$ antisymmetric stretching and symmetric stretching bands for $-\mathrm{CH}_{3}$, the band at around $2920 \mathrm{~cm}^{-1}$ was from $v_{\mathrm{C}-\mathrm{H}}$ antisymmetric stretching of $-\mathrm{CH}_{2}$, and the band at around 1220 $\mathrm{cm}^{-1}$ was from $v_{\mathrm{S}=\mathrm{O}}$ stretching. There were no similar bands in the spectrum of Ca/Al-Cl-LDH . For S1, S2, S3 and S4, the FT-IR spectra showed three bands at around 2959, 2920, 2850 and $1220 \mathrm{~cm}^{-1}$. These results indicate that $\mathrm{DS}^{-}$was successfully loaded in these samples.

The EA results for the Ca/Al-SDS-LDHs samples are shown in Table 2. Using the sulfur contents $\left(C_{\mathrm{S}}(\%)\right)$ of the samples and the molecular weight of SDS, the mass contents of $\mathrm{DS}^{-}\left(f_{\mathrm{DS}}{ }^{-}\right)$in the organic LDH samples were calculated. The mass of $\mathrm{DS}^{-}$loaded on the LDH samples was in the
Table 1 FT-IR spectral data for the samples

\begin{tabular}{lccc}
\hline \multicolumn{1}{c}{ Sample } & $2900-3000\left(\mathrm{~cm}^{-1}\right)$ & $2800-2900\left(\mathrm{~cm}^{-1}\right)$ & $1200-1300\left(\mathrm{~cm}^{-1}\right)$ \\
\hline Pure SDS & $2918.7,2956.7$ & 2850.5 & 1221.2 \\
S1 & $2922.4,2959.0$ & 2852.7 & 1219.9 \\
S2 & $2923.6,2959.0$ & 2853.3 & 1219.9 \\
S3 & $2923.6,2959.0$ & 2853.2 & 1219.9 \\
S4 & $2923.8,2959.1$ & 2853.4 & 1219.9 \\
Ca/Al-Cl-LDH & - & - & - \\
\hline
\end{tabular}

Table 2 Element analysis of the Ca/Al-SDS-LDHs

\begin{tabular}{ccccc}
\hline Sample & $\mathrm{Ca} / \mathrm{Al}$ ratio & $C_{\mathrm{C}}(\%)$ & $C_{\mathrm{S}}(\%)$ & $f_{\mathrm{DS}}{ }^{-\mathrm{a})}(\%)$ \\
\hline S1 & $2: 1$ & 30.4 & 5.7 & 47.1 \\
S2 & $1: 1$ & 41.5 & 7.9 & 65.3 \\
S3 & $1: 2$ & 41.4 & 7.8 & 64.7 \\
S4 & $1: 3$ & 40.4 & 7.4 & 61.2 \\
\hline
\end{tabular}

a) $f_{\mathrm{DS}}{ }^{-}=C_{\mathrm{S}}(\%) /\left(M_{\mathrm{S}} / M_{\mathrm{DS}}{ }^{-}\right)$.

following order: $\mathrm{S} 1<\mathrm{S} 2 \approx \mathrm{S} 3 \approx \mathrm{S} 4$.

The EA, FTIR and XRD analyses demonstrate that DS $^{-}$ was successfully inserted into the interlayer of all the Ca/Al-SDS-LDHs (S1-S4).

\subsection{Sorption isotherms}

The physical and chemical properties of nitrobenzene and naphthalene are listed in Table 3. These two compounds have similar molecular weights, but very different solubilities, octanol-water partition coefficients $\left(K_{\text {ow }}\right)$, and polarity. The $K_{\text {ow }}$ of naphthalene is 1995.3 , and the $K_{\text {ow }}$ of nitrobenzene is 70.8 , which indicates that naphthalene is more hydrophobic than nitrobenzene. The greater dipole moment of nitrobenzene (3.98) than naphthalene (0) shows nitrobenzene is more polar than naphthalene.

The sorption isotherms for nitrobenzene and naphthalene sorption from water by the Ca/Al-SDS-LDHs and $\mathrm{Ca} / \mathrm{Al}-\mathrm{Cl}$ LDH are shown in Figure 2. The stronger sorption of nitrobenzene and naphthalene onto the Ca/Al-SDS-LDHs than $\mathrm{Ca} / \mathrm{Al}-\mathrm{Cl}-\mathrm{LDH}$ illustrated that organic modification of the LDHs can enhance their sorption for aqueous organic contaminants.

From the sorption isotherms in Figure 2, the sorption of naphthalene was shown to be greater than that of nitrobenzene for all the LDH samples. This result is consistent with the hydrophobicities of these two compounds. The sorption strengths the Ca/Al-SDS-LDHs for nitrobenzene were in the order $\mathrm{S} 1>\mathrm{S} 4>\mathrm{S} 3>\mathrm{S} 2$, and those for naphthalene were in the

Table 3 The basic physical and chemical properties of the organic pollutants in this study

\begin{tabular}{cccccc}
\hline Organic material & Molecular weight & Solubility in water $(\mathrm{mg} / \mathrm{L})$ & $K_{\text {ow }}$ & Polarity & Polar \\
Nitrobenzene & 123.11 & 2090 & 70.8 & 3.98 \\
Naphthalene & 128.18 & 31.8 & 1995.3 & Non-polar \\
\hline
\end{tabular}



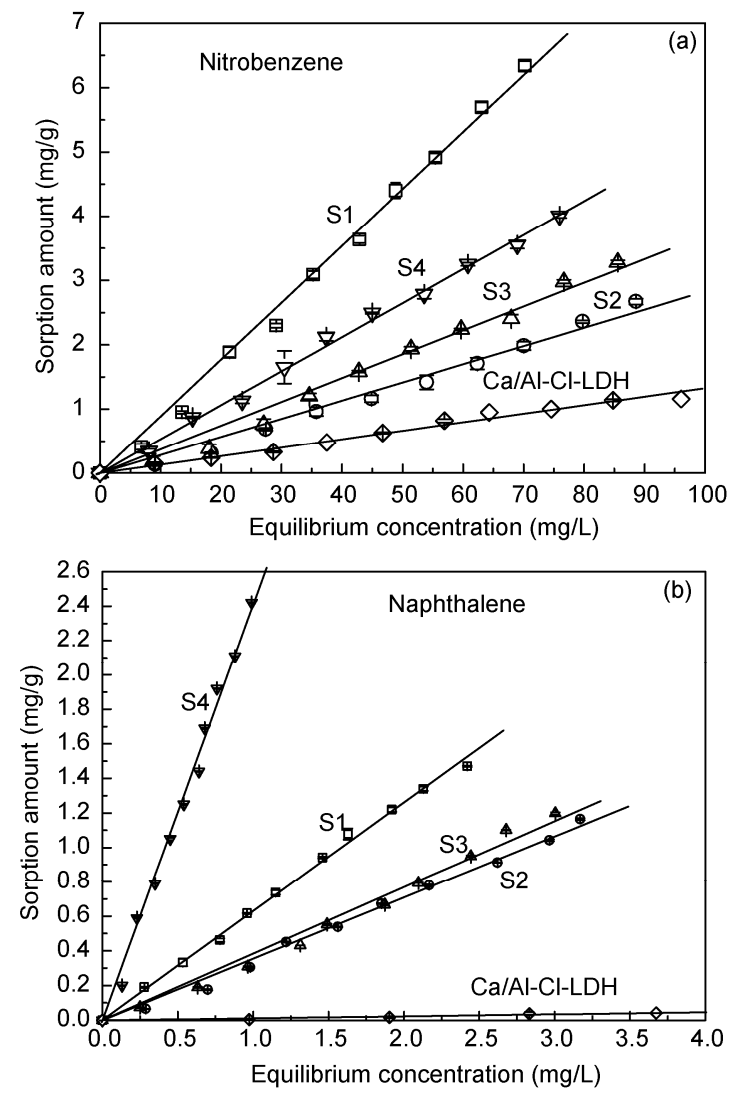

Figure 2 Sorption isotherms of nitrobenzene (a) and naphthalene (b) by the Ca/Al-SDS-LDHs and Ca/Al-Cl-LDH. The standards deviations are shown by the error bars.

order $\mathrm{S} 4>\mathrm{S} 1>\mathrm{S} 3>\mathrm{S} 2$. The XRD patterns of the Ca/Al-SDSLDHs (Figure 1), showed the crystal structure of S3 was not ordered, and the $d_{003}$ value of S2 was the low. These structure characteristics of S3 and S2 might contribute to their weak sorption of the organic contaminants. The good crystalline structure of S1 and the large interlayer spacing of S4 could assist their sorption of the organic contaminants. However, for nitrobenzene, the sorption by $\mathrm{S} 1$ was stronger than that by $\mathrm{S} 4$, while for naphthalene, the sorption by $\mathrm{S} 4$ was greater than by S1. Therefore, in addition to the hydrophobicity, other physical and chemical properties of the organic contaminants must affect their sorption by the $\mathrm{Ca} / \mathrm{Al}-\mathrm{SDS}-\mathrm{LDHs}$.

\subsection{Partition coefficients}

The sorption isotherms of nitrobenzene and naphthalene onto $\mathrm{Ca} / \mathrm{Al}-\mathrm{SDS}-\mathrm{LDH}$ were almost linear within the investigated concentration range of the solute. The shape of the sorption isotherm implied that the sorption was mainly controlled by the partition mechanism. This can be expressed by the following equations:

$$
\begin{gathered}
Q_{\mathrm{p}}=K_{\mathrm{p}} C_{\mathrm{e}}, \\
K_{\mathrm{oc}}=K_{\mathrm{p}} / f_{\mathrm{oc}},
\end{gathered}
$$

where $Q_{\mathrm{p}}(\mathrm{mg} / \mathrm{g})$ is the sorption mass; $C_{\mathrm{e}}(\mathrm{mg} / \mathrm{g})$ is the equilibrium concentration in the water; $K_{\mathrm{p}}$ is the partition coefficient; $K_{\mathrm{oc}}$ is the organic carbon standardized partition coefficient; and $f_{\mathrm{oc}}$ is the percentage content of organic carbon of Ca/Al-SDS-LDHs, which can be calculated from $f_{\mathrm{DS}}{ }^{-}$of the Ca/Al-SDS-LDHs. The values of $K_{\mathrm{p}}$ and $K_{\mathrm{oc}}$ were calculated using eqs. (1) and (2), and are listed in Table 4.

The $K_{\mathrm{p}}$ values for nitrobenzene sorption by the different $\mathrm{Ca} / \mathrm{Al}-\mathrm{SDS}-\mathrm{LDH}$ were in the order $\mathrm{S} 1>\mathrm{S} 4>\mathrm{S} 3>\mathrm{S} 2$, and those for naphthalene were in the order $\mathrm{S} 4>\mathrm{S} 1>\mathrm{S} 3>\mathrm{S} 2$. These results are consistent with the sorption isotherms. However, for the $K_{\text {oc }}$ values both nitrobenzene and naphthalene sorption by the different $\mathrm{Ca} / \mathrm{Al}-\mathrm{SDS}$-LDHs were in the order $\mathrm{S} 1>\mathrm{S} 4>\mathrm{S} 3>\mathrm{S} 2$. The $K_{\mathrm{oc}}$ value decreased as the $f_{\mathrm{oc}}$ value of the $\mathrm{Ca} / \mathrm{Al}-\mathrm{SDS}-\mathrm{LDHs}$ increased. This phenomenon was also reported for the sorption by organobentonites [29]. In the sorption of organic compounds onto organobentonites, where bentonite is intercalated by surfactant cations, the $K_{\mathrm{oc}}$ increased as the $f_{\text {oc }}$ increased, until $K_{\text {oc }}$ reached a maximum at a particular $f_{\mathrm{oc}}$ value. After that point, $K_{\mathrm{oc}}$ decreased with further increases in the $f_{\text {oc }}$, which was thought to be caused by steric hindrance of surfactant cations in the interlayer of organobentonites [29]. This may occur because organic LDHs and organobentonites form organic phases in their interlayer. The similarity of their interlayer structures might result in the similar sorption mechanisms for organic contaminants. The greater $K_{\mathrm{oc}}$ value of $\mathrm{S} 1$ than $\mathrm{S} 4$ might also result from the steric hindrance of $\mathrm{DS}^{-}$in the interlayer because the $f_{\text {oc }}$ of $\mathrm{S} 4$ was higher than that of S1.

\subsection{Polarity effects}

Sorption isotherms of organic contaminants onto $\mathrm{Ca} / \mathrm{Al}-$ SDS-LDHs $\left(Q-C_{\mathrm{e}} / S_{\mathrm{w}}\right.$ plots) (Figure 3$)$ were plotted, where $C_{\mathrm{e}} / S_{\mathrm{w}}$ is the ratio of equilibrium concentration to solute aqueous solubility $\left(S_{\mathrm{w}}\right)$.

In Figure 3, $C_{\mathrm{e}} / S_{\mathrm{w}}$ was used to eliminate the effect of hydrophobic organic contaminants on sorption, and this was used to determine the interactions between the sorbents and

Table $4 K_{\mathrm{p}}$ and $K_{\mathrm{oc}}$ of different Ca/Al-SDS-LDHs

\begin{tabular}{cccccc}
\hline Sample & $f_{\text {oc }}(\%)$ & $K_{\mathrm{p}}($ nitrobenzene $)$ & $K_{\mathrm{p}}($ naphthalene $)$ & $K_{\text {oc }}($ nitrobenzene $)$ & 0.29 \\
\hline S1 & 30.4 & 0.09 & 0.63 & 0.07 \\
S2 & 41.5 & 0.03 & 0.36 & 0.08 & 0.09 \\
S3 & 41.4 & 0.04 & 0.39 & 0.93 & 0.13 \\
S4 & 40.4 & 0.05 & 0.73 & 1.82 \\
\hline
\end{tabular}




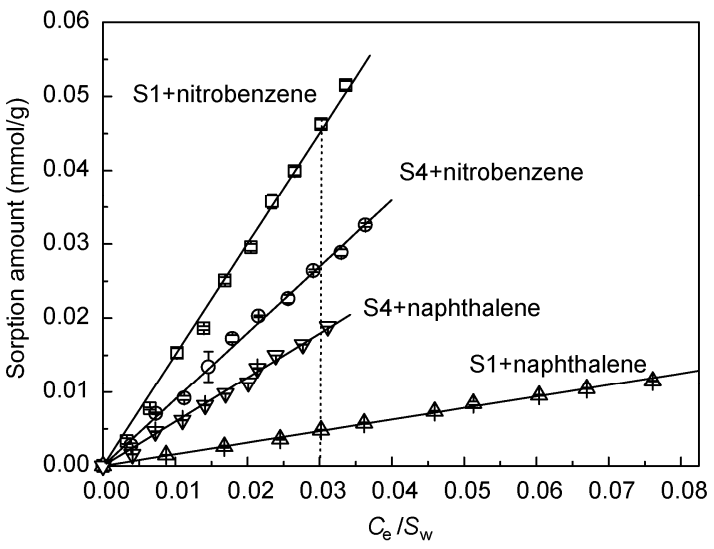

Figure 3 Sorption isotherms of nitrobenzene and naphthalene by S1 and $\mathrm{S} 4\left(Q-C_{\mathrm{e}} / S_{\mathrm{w}}\right.$ plots). The standard deviations are shown by the error bars.

the organic contaminants. After eliminating the hydrophobic effect, it was obvious that both S1 and S4 had stronger sorption of nitrobenzene than naphthalene. A similar polarity effect was observed for the sorption of organic compounds by organobentonites [30]. After eliminating the hydrophobic effect, the sorption of strongly polar compounds (aniline or phenol) was greater than that of a weakly polar compound (toluene) by organobentonites [30]. For the contaminants used in this study, the polarity of nitrobenzene $(D=3.98)$ is greater than naphthalene $(D=0)$. Therefore, it can be inferred that the sorption of nitrobenzene and naphthalene by $\mathrm{Ca} / \mathrm{Al}-\mathrm{SDS}-\mathrm{LDH}$ s was dependent mainly on polar effects after elimination of the hydrophobic effect. The stronger sorption of nitrobenzene and the weaker sorption of naphthalene onto $\mathrm{S} 1$ relative to the sorption onto S4 (Figure 2) might be caused by the co-effect of the polarities and hydrophobicities of these two contaminants.

As shown in Figure 3, the difference between the sorption of nitrobenzene and naphthalene for S1 was much greater than the difference for S4. For example, for $\mathrm{S} 1$ at $C_{\mathrm{e}} / S_{\mathrm{w}}=0.03$, the sorption of nitrobenzene $(0.045 \mathrm{mmol} / \mathrm{g})$ was almost 10 times greater than the sorption of naphthalene $(0.004 \mathrm{mmol} / \mathrm{g})$. However, for $\mathrm{S} 4$ at $C_{\mathrm{e}} / S_{\mathrm{w}}=0.03$, the sorption of nitrobenzene $(0.026 \mathrm{mmol} / \mathrm{g})$ was only 1.5 times greater than the sorption of naphthalene $(0.017 \mathrm{mmol} / \mathrm{g})$. These results imply that the difference in S1's affinity to nitrobenzene and naphthalene is much greater than that of S4 to the same compounds. Figure 3 exhibited a polarity effect for the sorption of organic contaminants onto S1 and $\mathrm{S} 4$, and it can be concluded that S1 was more polarityselective than $\mathrm{S} 4$.

This work was supported by the National Natural Science Foundation of China (20907029), the Innovative Project of Shanghai Municipal Education Commission (10YZ07), and the Key Subject of Shanghai Municipality (S30109).

1 Drits V A, Sokolova T N, Sokolova G V, et al. New members of the hydrotalcite-manasseite group. Clays Clay Miner, 1987, 35: 401-417

2 Cavani F, Trifirò F, Vaccari A. Hydrotalcite-type anionic clays: Preparation, properties and applications. Catal Today, 1991, 11: 173

3 Stephen P, Newman S P, Jones W. Synthesis, characterization and applications of layered double hydroxides containing organic guests. New J Chem, 1998, 22: 105-115

4 Khan A I, O'Hare D. Intercalation chemistry of layered double hydroxides: Recent developments and applications. J Mater Chem, 2002, 12: $3191-3198$

5 Simon C. The intercalation of carboxylic acids into layered double hydroxides: A critical evaluation and review of the different methods. Solid State Ionics, 1997, 98: 73-84

6 Martina M, Klaus B, Gerhard L. Anion-exchange reactions of layered double hydroxides. Inorg Chem, 1990, $29: 5201-5207$

7 Carrado K A, Forman J E, Botto R E, et al. Incorporation of phthalocyanines by cationic and anionic clays via ion exchange and direct synthesis. Chem Mater, 1993, 5: 472-478

8 You Y W, Vance G F, Zhao H T. Selectivity and molecular sieving effects of organic compounds on the intercalate of $\beta$-cyclodextrin and layered double hydroxide. Clays Clay Miner, 1998, 46: 712-718

9 You Y W, Zhao H T, Vance G F. Surfactant-enhanced adsorption of organic compounds by layered double hydroxides. Colloids Surf A, 2002, 205: 161

10 Hermosín M C, Pavlovic I, Ulibarri M A, et al. Hydrotalcite as sorbent for trinitrophenol: Sorption capacity and mechanism. Water Res, 1996, 30: 171-177

11 Bruna F, Pavlovic I, Barriga C, et al. Adsorption of pesticides carbetamide and metamitron on organohydrotalcite. Appl Clay Sci, 2006, 33: $116-124$

12 Celis R, Koskinen W C, Hermosin M C, et al. Triadimefon intercalations with organoclays and organohydrotalcites. Soil Sci Soc Am J, 2000, 64: 36-43

13 Esumi K, Yamamoto S. Adsorption of sodium dodecyl sulfate on hydrotalcite and adsolubilization of 2-naphtol. Colloids Surf A, 1998, 137: $385-388$

14 Mohamed B, Lafjah M, Quali M S, et al. Basic dye removal from aqueous solutions by dodecyl sulfate and dodecyl benzene sulfonateintercalated hydrotalcite. J Hazard Mater, 2008, 153: 911-918

15 Moujahid E M, Inacio J, Besse J P, et al. Adsorption of styrene sulfonate vs polystyrene sulfonate on layered double hydroxides. Micropor Mesopor Mat, 2003, 57: 37-46

16 Li F, Wang Y F, Yang Q Z, et al. Study on adsorption of glyphosate (N-phosphono-methyl glycine) pesticide on $\mathrm{Mg}$ Al-layered double hydroxides in aqueous solution. J Hazard Mater, 2005, 125: 89-95

17 You Y W, Zhao H T, Vance G F. Hybrid organic-inorganic derivatives of layered double hydroxides and dodecyl benzenesulfonate: Preparation and adsorption characteristic. Chem Mater, 2002, 12: 907-912

18 Herrero M, Labajos F M, Rives V. Size control and optimisation of intercalated layered double hydroxides. Appl Clay Sci, 2009, 42: $510-518$

19 Moyo L, Nontete N, Focke W W. A critical assessment of the methods for intercalating anionic surfactants in layered double hydroxides. J Mater Sci, 2008, 43: 6144-6158

20 Tomohito K, Yuuichi T, Takashi Y, et al. Preparation and characterization of $\mathrm{Mg}$ - $\mathrm{Al}$ layered double hydroxides intercalated with benzene sulfonate and benzene disulfonate. Micropor Mesopor Mat, 2008, 114: 410-415

21 Esumi K, Yamamoto S. Adsorption of sodium dodecyl sulfate on hydrotalcite and adsolubilization of 2-naphtol. Colloids Surf A, 1998, 137: $385-388$

22 Bruna F, Pavlovic I, Barriga C, et al. Adsorption of pesticides carbetamide and metamitron on organohydrotalcite. Appl Clay Sci, 2006, 33: $116-124$

23 Bouraada M, Belhalfaoui F, Ouali M S, et al. Sorption study of an acid dye from an aqueous solution on modified $\mathrm{Mg}$-Al layered double hydroxides. J Hazard Mater, 2009, 163: 463-467

24 Wang B, Zhang H, Evans D G, et al. Surface modification of layered double hydroxides and incorporation of hydrophobic organic 
compounds. Mater Chem Phys, 2005, 92: 190-196

25 You Y W, Zhao H T, Vance G F. Surfactant-enhanced adsorption of organic compounds by layered double hydroxides. Colloids Surf A, 2002, 205: 161-172

26 Klumppa E, Contreras-Ortega C, Klahre P, et al. Sorption of 2,4-dichlorophenol on modified hydrotalcites. Colloids Surf A, 2003, 230: $111-116$

27 Zhao H, Nagy K L. Dodecyl sulfate-hydrotalcite nanocomposites for trapping chlorinated organic pollutants in water. J Colloid Interf Sci, 2004, 274: 613-624
28 Xiong Z G, Xu Y M. Immobilization of palladium phthalocyanine sulfonate onto anionic clay for sorption and oxidation of 2,4,6trichlorophenol under visible light irradiation. Chem Mater, 2007, 19: 1452-1458

29 Zhu L Z, Zhu R L, Xu L H, et al. Influence of clay charge densities and surfactant loading amount on the microstructure of CTMAmontmorillonite hybrids. Colloids Surf A, 2007, 304: 41-48

30 Ruan X X, Zhu L Z, Chen B L. Adsorptive characteristics of the siloxane surfaces of reduced-charge bentonites saturated with tetramethylammonium cation. Environ Sci Technol, 2008, 42: 7911-7917

Open Access This article is distributed under the terms of the Creative Commons Attribution License which permits any use, distribution, and reproduction in any medium, provided the original author(s) and source are credited. 